\title{
Fortalecimento de valores culturais para a construção da identidade individual e coletiva
}

\author{
Strengthening cultural values for the construction of individual and collective identity \\ Fortalecimiento de valores culturales para la construcción de la identidad individual y colectiva
}

Winthney Paula Souza Oliveira ${ }^{1 *}$, Mônica dos Santos de Oliveira ${ }^{1}$, Amanda Thais Franco Oliveira ${ }^{1}$, Karla Fernanda Menezes Rodrigues ${ }^{1}$, Luanna Roberta Lima de Oliveira ${ }^{1}$, Pedro Wilson Ramos da Conceição', Maysa Milena e Silva Almeida ${ }^{1}$, Francisca Tatiana Dourado Gonçalves ${ }^{1}$.

\section{RESUMO}

Objetivo: Descrever a experiência vivenciada com a aplicabilidade do projeto "Fortalecimento de valores culturais para a construção da identidade individual e coletiva". Relato de experiência: Trata-se de um relato de experiência, executado no Serviço de Convivência e Fortalecimento de Vínculos do Centro de Referência de Assistência Social - CRAS com 20 crianças e adolescentes. Resultando na Valorização da história, cultura, tradição e resgate dos valores éticos indispensáveis e fundamentais para uma plena formação social contribuindo para constituição e formação do indivíduo crítico, ativo e participativo, a transmissão de conhecimentos do passado aliada aos conhecimentos presentes permite uma fusão dos conteúdos originando a identidade cultural coletiva e individual com marcas próprias em cada sociedade e em cada sujeito. Considerações finais: As crianças necessitam conversar sobre princípios morais, conhecer e valorizar suas práticas para que o contexto social em que se vive seja berço de informações sistematizadas, multiplicadas e repassadas para que ocorra a perpetuação dos ensinamentos. É fundamental que a criança e adolescente disponha de diálogos sobre a importância de tratar o próximo da melhor maneira possível e valorizar relações saudáveis, seja no plano individual, com a inserção em si mesmo dos princípios ou no vivenciar e compartilhar coletivo, por meio das ações de repasse, condutas e comportamentos que evidenciam os valores internalizados.

Palavras Chave: Valores sociais, Cultura, Construção Social da Identidade.

\begin{abstract}
Objective: To describe the lived experience with the applicability of the project Strengthening of cultural values for the construction of the individual and collective identity. Experience report: It is an experience report, executed in the Service of Coexistence and Strengthening of Links of the Center of Reference of Social Assistência - CRAS writ 20 chilre anda adolescents. Resulting to value the history, culture, tradition and to rescue the ethical values indispensable and fundamental for a full social formation contributes to the constitution and formation of the critical, active and participative individual, the transmission of knowledge of the past allied to the present knowledge allows a fusion of the contents originating the collective and individual cultural identity with own brands in each society and in each subject. Final consideration: Children, young people and adults need to talk about moral principles, to know and value their practices so that the social context in which they live is the cradle of systematized information, multiplied and passed on to perpetuate the teachings. It is essential that the child and the adolescent have dialogues on the importance of treating their neighbors in the best possible way and value healthy relationships, be it on an individual level, with the insertion of the principles in oneself or in the collective experience and sharing, through actions of passthrough, behaviors and behaviors that evidence internalized values.
\end{abstract}

Keywords: Social values, Culture, Social Construction of Identity.

${ }^{1}$ Centro Universitário de Ciências e Tecnologia do Maranhão - UNIFACEMA, Caxias-Maranhão.

*E-mail: winthnew00@hotmail.com 


\section{RESUMEN}

Objetivo: Describir la experiencia vivenciada con la aplicabilidad del proyecto Fortalecimiento de valores culturales para la construcción de la identidad individual y colectiva. Relato de experiencia: Se trata de un relato de experiencia, ejecutado en el Servicio de Convivencia y Fortalecimiento de Vínculos del Centro de Referencia de Asistencia Social - CRAS con 20 niños y adolescentes. Resultando em la valorización de la historia, cultura, tradición y rescatar los valores éticos indispensables y fundamentales para una plena formación social contribuye a la constitución y formación del individuo crítico, activo y participativo, la transmisión de conocimientos del pasado aliada a los conocimientos presentes permite una fusión de los contenidos originando la identidad cultural colectiva e individual con marcas propias en cada sociedad y en cada sujeto. Consideraciones finales: Los niños, jóvenes y los adultos necesitan conversar sobre principios morales, conocer y valorar sus prácticas para que el contexto social en que se vive sea cuna de informaciones sistematizadas, multiplicadas y repasadas para que ocurra la perpetuación de las enseñanzas. Es fundamental que el niño y adolescente disponga de diálogos sobre la importancia de tratar al prójimo de la mejor manera posible y de valorar relaciones saludables, sea en el plano individual, con la inserción en sí mismo de los principios o en el vivenciar y compartir colectivo, a través de las acciones de repase, conductas y comportamientos que evidencian los valores internalizados.

Palabras Clave: Valores sociales, Cultura, Construcción Social de la Identidad.

\section{INTRODUÇÃO}

O Brasil, é um país com muitas misturas de raças, costumes e tradições, cada comunidade, cada povo que constitui a nação possui marcas próprias. A diversidade cultural existente apresenta conjuntos peculiares, em cada grupo valores que se complementam e se contrapõem são evidenciados. Sentir-se pertencente, produto e produtor da vida social perpassa pelos aspectos interligados às experiências passadas e presentes, oriundas das experiências diárias, que serão refletidas no futuro por meio do entrelaçamento do elo destes aspectos vivenciados (BRANCO AU, 2016).

A cultura é uma construção sócio histórica transgeracional (HUTZ CS. et al. 2010). Brandão CR (2002), afirma que a cultura está presente no dialeto, na comida, nas percepções, vivências e na forma em que os sentidos e significados vão sendo atribuídos ao mundo. Os indivíduos recebem ensinamentos, crenças, valores, costumes e tradições de forma intergeracional e intrageracional. A transmissão de conhecimentos do passado contribui para constituição e formação do indivíduo do presente, os conteúdos fundem-se dando origem a identidade cultural coletiva, com marcas próprias em cada sociedade. Faz-se necessário manter, valorizar a história, cultura, tradição e resgatar os valores éticos indispensáveis e fundamentais para uma plena formação social (MAGALHÃES LDR 2016).

A transmissão dos sistemas simbólicos, sócio - históricos e culturais ocorre por meio do processo de interação, uma pluralidade de práticas de aprendizagem que ressaltam a concepção de que toda educação é cultura. (SILVA NN, 2011). As crianças, jovens e os adultos necessitam conversar sobre princípios morais, conhecer e valorizar suas práticas para que o contexto social em que se vive seja berço de informações sistematizadas, multiplicadas e repassadas para que ocorra a perpetuação dos ensinamentos. È fundamental que a criança e adolescente disponha de diálogos sobre a importância de tratar o próximo da melhor maneira possível e valorizar relações saudáveis, seja no plano individual, com a inserção em si mesmo dos princípios ou no vivenciar e compartilhar coletivo, por meio das ações de repasse, condutas e comportamentos que evidenciam os valores internalizados (PINTO RG e BRANCO AU, 2009).

O objetivo do projeto de intervenção consistiu-se em fortalecer a identidade dos indivíduos, a valorização da família, auto reconhecimento, autovalorização e perpetuação de boas práticas sociais e valores morais e éticos. 


\section{RELATO DE EXPERIÊNCIA}

Trata-se de um relato de experiência acerca das atividades desenvolvidas com os assistidos do Centro de Referência de Assistência Social - CRAS. A escolha das ações direcionadas ao público alvo são oriundas da análise situacional da população atendida, a execução das ações e medidas interventivas pautaram-se na demanda social comunitária apresentada pelos assistidos. Nesse sentido, realizou-se diagnóstico, sondagem inicial acerca das situações de vulnerabilidade, riscos e potencialidades sociais, a realidade da comunidade e o perfil dos assistidos foram analisados para levantamento de informações, e assim, delineadas as ações construídas coletivamente com a clientela e grupo de estagiários, inserindo, dessa forma, as ações. As práticas desenvolvidas contribuíram para o rompimento de barreiras, vulnerabilidade social, bem como a garantia do empoderamento social e participação ativa da comunidade.

Fortalecimento de valores culturais para a construção da identidade individual e coletiva" trata-se de um projeto oriundo do estágio básico em Psicologia Social e Comunitária do curso bacharelado em Psicologia do Centro Universitário de Ciências e Tecnologia do Maranhão - UNIFACEMA, o projeto fora realizado no Centro de Referência e Assistência Social - CRAS com o intuito de evidenciar que o recebimento e repasse de informações acerca da peculiaridade e singularidade dos elementos éticos de uma sociedade e cultivo de bons sentimentos e condutas permite uma melhor compreensão da vida.

O projeto envolveu 20 crianças e adolescentes participantes do Serviço de Convivência e Fortalecimento de Vínculos do CRAS Caldeirões, o processo interventivo aconteceu em 08 encontros totais. A primeira etapa consistiu em dois (02) encontros para observação institucional com visita às instalações do equipamento, interação e socialização com crianças e adolescentes do Serviço de Convivência e Fortalecimento de Vínculos do CRAS Caldeirões, participação nas atividades planejadas pelas orientadoras sociais para possibilitar interação e observação do espaço e dos assistidos. Após analisar e delinear o perfil dos assistidos ações de intervenção foram planejadas.

O terceiro encontro intitulado "Um dia de lazer para aprender brincando" promoveu o resgate cultural de brincadeiras tradicionais através de uma manhã de lazer lúdica em alusão ao dia das crianças, a socialização, a interação, o desenvolvimento das habilidades de improviso, a expressão livre do corpo e movimento foram aprimoradas através do desenvolvimento de atividades diversificadas pautadas na formação e desenvolvimento de indivíduos ativos e participantes na sociedade, por meio de contação de histórias, encenação, brincadeiras e cantigas de roda, ressaltando os aspectos para geração e manutenção da qualidade de vida coletiva, buscou-se desenvolver e aprimorar a cooperação, o companheirismo, a solidariedade e a partilha, evidenciando também a importância das atividades físicas para manutenção da saúde, motricidade, lateralidade, noção de tempo e espaço.

O quarto encontro "O despertar da solidariedade" destacou a importância do cultivo de bons sentimentos para a formação e desenvolvimento das crianças como cidadãs, buscou-se através de bate papo com os assistidos verificar quais os conceitos e conhecimentos dispunham sobre o valor a ser trabalhado no dia. Procedeu-se com a leitura de um conto infantil "O pinguim que gostava do calor" destacando a importância e nobreza de oferecer auxílio ao outro, apresentando a solidariedade como uma condição espontânea e que deve ser cultivada. Em seguida, os assistidos realizaram recortes e desenhos para evidenciar os sentimentos e emoções despertados pelo conto, as crianças apresentaram suas produções.

O quinto encontro "Preconceito, discriminação e inclusão" promoveu uma roda de conversa sobre deficiência, preconceito e discriminação com linguagem clara e compatível à faixa etária do público alvo, para repassar informações acerca do respeito ao outro, tolerância, compreensão, bem como verificar o que as crianças e adolescentes compreendiam sobre a temática. Realizou-se a dinâmica "Sentindo na pele", simulando o dia a dia de uma pessoa com deficiência visual, ao final da dinâmica os assistidos narraram suas experiências, fora ressaltado o respeito às pessoas com deficiência, o respeito, o cuidado e acolhimento ao outro independente de suas necessidade ou limitações, em seguida realizou-se a leitura do conto "O leão que queria reinar no topo do mundo" a fim de evidenciar a importância da generosidade como forma de ajudar sem pedir nada em troca. 
O sexto encontro "A ambição" iniciou-se com a leitura do conto "O castelo de ouro" ressaltando-se os pontos positivos e negativos do sentimento ambição, destacando que o desejo de poder e riqueza acima de tudo constitui-se como prejudicial, no entanto, é necessário que todos possuam uma dose de ambição, pois esta motiva e impulsiona os indivíduos para a busca e realização de sonhos e superação de dificuldades. Em seguida, as crianças tiveram que escolher brinquedos na caixa lúdica para que as estagiárias observassem questões ligadas ao respeito, às regras, esperar a vez e o compartilhar, diante das situações apresentadas algumas intervenções do grupo de estagiárias foi necessário a fim de instalar, manter e/ou fortalecer o respeito ao direito dos outros e deveres para o bom desempenho social como cidadão ativo.

O sétimo encontro "Afeto" trabalhou a família, o afeto, o respeito e a compreensão, foi solicitado que os assistidos relatassem como é o dia a dia com a família, com quem vivem e o que fazem rotineiramente. Em seguida os alunos receberam materiais como: papeis, tintas, pinceis, lápis de cor e giz de cera, para que produzissem uma atividade artística para ser entregue a um membro familiar como demonstração de carinho, amor e respeito, a fim de fortalecer os vínculos familiares. Realizou-se a leitura do conto "O castelo de gelo" e estabeleceu-se uma conexão com o espaço familiar, ressaltando-se os cuidados familiares, a proteção dos pais pelos seus filhos e sobre a necessidade de estabelecer uma relação de confiança, respeito e cordialidade com os membros familiares.

O oitavo encontro "Despedida" marcou a finalização do processo de estágio no CRAS, trabalhou-se o conto "Um senhor amigo" exemplificando a necessidade de valorizar e cultivar relações saudáveis, destacando que o fim pode ser ressignificado e visto como um novo recomeço, a importância do respeito e que este deve ser sempre cultivado para que boas relações sejam mantidas, dessa forma as boas lembranças sempre farão parte da trajetória. Os assistidos receberam a informação que o estágio se findou, foram executadas brincadeiras tradicionais, competições e como lembrança de estágio e forma de agradecimento pela acolhida e o tempo de dedicação recíproca entre assistidos, funcionários e estagiárias fora entregue um porta retrato com uma foto que contemplou um momento marcante do período do estágio, em seguida houve o lanche coletivo marcando a despedida.

\section{DISCUSSÃO}

A cultura constitui-se como um aglomerado de informações peculiares de um povo, abriga características transmitidas ao longo do tempo, através das experiências pessoais e sociais, diversos aspectos e costumes são repassados e trocados entre as gerações (BAPTISTA JA, 2010). A Organização das Nações Unidas para a Educação, a Ciência e a Cultura - UNESCO, na Declaração Universal sobre a Diversidade Cultural, define cultura como um amplo conjunto de ações que permeiam desde bens palpáveis, materiais até aspectos subjetivos, espirituais e cognitivos que podem ser repassados por meio das tradições, crenças de um povo ao longo das gerações, ressaltando-se que cultura é um modo de viver junto permeado por valores (UNESCO, 2002).

As intervenções desenvolvidas possibilitaram o repasse de atitudes de desenvolvimento da afetividade, companheirismo, valorização do semelhante, ética, reflexão, exercício da cidadania e respeito entre crianças e adolescentes assistidos pelo Centro de Referência de Assistência Social - CRAS bem como a extensão dos valores trabalhados para a família e sociedade de forma a permitir a perpetuação e a multiplicação da cultura e valores morais, contribuindo com a formação social e individual das crianças e adolescentes, permitindo a reflexão sobre o respeito entre os semelhantes e diferentes, repasse de conhecimentos culturais por meio de brincadeiras e cantigas tradicionais, auxilio na formação de valores éticos e morais para o adequado exercício da cidadania, favorecimento e construção de pessoas críticas e responsáveis para um adequado convívio social permeado por contribuições que aperfeiçoem competências que possibilitem que a comunidade pense sobre suas ações, sobre os problemas buscando estratégias para resolução e disseminação das informações, empoderando os sujeitos tornando-os críticos e autônomos. 
O projeto permitiu verificar a autonomia dos assistidos através do estudo da história de valores culturais, fortalecimento da relação familiar, das percepções e das opiniões durante a leitura dos contos, estimulou-se nos assistidos a construção de suas subjetividades pautados no respeito a si, a outro, ao local e como vivem, como constroem seus artefatos e a si mesmos, como sentem e pensam, além de analisar, compreender e conhecer a realidade dos assistidos bem como auxiliar no processo de desenvolvimento humano, capacitando os indivíduos para uma visão positiva de si e do seu meio, tornando-os capazes de buscar mudanças sociais, reconhecendo suas potencialidades e competências para a construção e rumo de suas vidas. Destacandose assim a importância do projeto para a socialização e o fortalecimento de valores para a formação da identidade das crianças através da contação de história, que como aponta Marcos ANB (2014), instiga a imaginação, a criatividade, a oralidade, incentiva o gosto pela leitura, contribui na formação da personalidade da criança envolvendo o social e o afetivo.

Por meio das ações, despertou-se a produtividade, participação, partilha de conhecimentos, qualidade de vida e bem-estar. É de suma importância reconhecer que a intervenção promoveu aos assistidos a exploração da ludicidade, desenvolvimento da atenção, uso da imaginação e encenação aspectos ressaltados e observados através da contação de histórias, os assistidos puderam desenvolver as habilidades de improviso, socialização e interação. A participação ativa da comunidade alvo se deu ao longo de todo o processo, os assistidos puderam compartilhar sua história de vida e relatar suas relações sociais.

Consultando diferentes autores, tais como Abramovich (1995) e Oliveira (2002), constatou-se que, para as crianças os jogos e brincadeiras são atividades proveitosas para o seu desenvolvimento. Para Moreno (2009), através do lúdico a criança sente-se estimulada e, sem perceber, vai se desenvolvendo e construindo seu conhecimento. Vygotsky (2000) considera que através dos jogos e brincadeiras nos quais se percebe a socialização e a vivência lúdica favorecem o aprendizado de regras, movimentos e a expressão corporal.

Aplicar ações e intervenções entre as crianças e os adolescentes participantes do Serviço de Convivência e Fortalecimento de Vínculos do CRAS Caldeirões em Caxias - MA permitiu ampliar a socialização, os conhecimentos da realidade social e cultural, bem como propiciar um desenvolvimento integral de suas identidades, formando cidadãos conhecedores de condutas norteadoras capazes de romper o preconceito, a discriminação e a exclusão, garantindo uma maior autonomia, formação pessoal e social.

A cultura é toda criação humana resultante do processo de transmissão e recebimento de simbologias, traços e marcas incorporadas e acumuladas por várias gerações, sendo mantida e preservada no meio social dando continuidade ao processo de transmissão dos modos de vida singulares dentro do grupo com similitudes e dissimilitudes entre os demais grupos formados socialmente (LARAIA RB, 2003). É através da cultura que os povos se diferenciam, é um processo de constituição coletiva, dinâmica que promove alterações, modificações e evoluções no meio e nos indivíduos (BATISTA JA, 2010). Conhecer, perceber e entender a diversidade cultural e social, permite a valorização dos traços históricos de um povo, desenvolve atitudes de respeito e dessa forma permite o rompimento do ciclo de preconceito e discriminação por carência de conhecimento das pluralidades sociais (MAGALHÃES LDR, 2016).

A cultura, através dos costumes, tradições, hábitos e relações sociais auxilia no processo de construção da identidade pessoal, ela é expressa por meio de marcas e características oriundas da tradição, herança cultural e incorporação de elementos atuais. A identidade é uma construção, não é um elemento fixo, imutável, acabado ou definitivo (SILVA NN, 2009).

A cultura é acumulativa, os indivíduos aglomeram uma coletânea de conhecimentos oriundas do processo de interação homem - homem e homem - natureza e dessa forma assimilam, perpetuam e integram à sua prática novas e velhas ações (DUARTE N; MARTINS LM, 2012). São essas coletâneas de conteúdos, únicos e autênticos que expressam as diferenças coletivas e individuais, dessa forma fortalece-se a concepção de que se deve preservar o passado para que seja um instrumento de ligação, mediação e entendimento do presente e futuro, valorizar as memórias de um povo permite o respeito à sua gênese e essência formadora e transformadora ( BRANCO AU, 2016). 
A identidade é uma marca característica que diferencia as pessoas, percorre os traços físicos, as formas de ser, agir e pensar. A construção da identidade e da autonomia tem sua gênese a partir do convívio social através dos conhecimentos repassados e peculiaridades presentes na sociedade por meio das trocas estabelecidas ainda na infância, no processo de imitação, observação e assimilação. A família é a primeira instituição social e dela partem as transmissões dos valores, costumes e moral. Os valores permitem o processo de reflexão quanto as ações externadas pelas pessoas, são eles que evidenciam expressam o sentido das ideias regidas e obtidas no berço comunitário, exemplifica o pensamento social e individual (ZABALZA M, 2000). O processo de socialização assegura a perpetuação, transmissão e internalização dos valores e da cultura. É preciso despertar, a autonomia, criticidade e criatividade como forma de contribuir na construção da identidade pautada nos costumes sociais de um povo, direitos humanos e éticos, para que a solidariedade, empatia, generosidade e afeto possam ser despertados e perpetuados no meio social (MAGALHÃES LDR, 2016).

\section{CONSIDERAÇÕES FINAIS}

Com o estudo constatou-se que as crianças e adolescentes assistidos no CRAS tiveram a oportunidade de fortalecer o processo de construção social de suas identidades, individuais e coletivas, respeitou-se o saber próprio da comunidade e valorizou-se a cada encontro suas experiencias para facilitação e incorporação de mudanças por meio do repasse e fortalecimento dos valores que permitiram o processo de reflexão em relação as ações externadas no berço individual e comunitário, despertou-se a autonomia, criticidade, criatividade e pautando-se nos costumes sociais de um povo, direitos humanos e éticos, para que a solidariedade, empatia, generosidade e afeto pudessem ser despertados e perpetuados no meio social. As ações foram pautadas no respeito, integrando ativamente os participantes, fortalecendo a identidade, singularidade, ofertando espaços para expressão de suas convicções, pensamentos, despertando a conscientização e assegurando direitos e conhecimentos para a busca de soluções e melhor qualidade de vida individual e coletiva através da participação e colaboração grupal.

\section{REFERÊNCIAS}

1. ABRAMOVICH F. Literatura Infantil: gostosuras e bobices. São Paulo: Scipione, 1995.

2. ARAUJO WA et al. Desenvolvimento local, turismo e populações tradicionais: elementos conceituais e apontamentos para reflexão. Interações (Campo Grande), Campo Grande, v. 18, n. 4, p. 5-18, Dec. 2017.

3. BRANCO AU. Crenças e práticas culturais: co-construção e ontogênese de valores sociais. Pro-Posições, [S.I.], v. 17, n. 2, p. 139-155, fev. 2016. ISSN 1982-6248.

4. BATISTA JA. Reflexões sobre o conceito antropológico de cultura. Revista Saber Eletrônico, Jussara, 2010. $102-109$.

5. BRANDÃO CR. A educação como cultura. Campinas: Mercado de Letras, 2002.

6. DUARTE N e MARTINS LM. As contribuições de Aleksei Nikolaevich Leontiev para o entendimento da relação entre educação e cultura em tempos de relativismo pós-moderno. EDUCAÇÃO E CULTURA: LIÇÕES HISTÓRICAS DO UNIVERSO PANTANEIRO, 2012.

7. HUTZ CS, et al. Avanços em psicologia comunitária e intervenções psicossociais. 2010. São Paulo: Casa do Psicólogo.

8. LARAIA RB. Cultura: um conceito antropológico. Rio de Janeiro: Jorge Zahar Editor, 2003.

9. MATEUS ANB et al. A importância da contação de história como prática educativa na educação infantil. Pedagogia em Ação, [S.I.], v. 5, n. 1, out. 2014. ISSN 2175-7003.

10. MAGALHÃES LDR. História, memória e a educação: relações consensuais e contraditórias. Revista HISTEDBR Online, Campinas, SP, v. 16, n. 67, p. 165-174, jul. 2016. ISSN 1676-2584.

11. MORENO LA. O Lúdico e a Contação de Histórias na Educação Infantil. Cadernos de Pesquisa Interdisciplinar em Ciências Humanas, Florianópolis, v. 10, n. 97, p. 228-241, nov. 2009. ISSN 1984-8951.

12. OLIVEIRA ZR. Educação infantil: fundamentos e métodos. São Paulo: Cortez, 2002. (Coleção Docência em Formação).

13. ORGANIZAÇÃO DAS NAÇÕES UNIDAS PARA EDUCAÇÃO, CIÊNCIA E CULTURA (UNESCO). Declaração Universal sobre a diversidade cultural. 2002.

14. PINTO RG e BRANCO AU. Práticas de socialização e desenvolvimento na educação infantil: contribuições da psicologia sociocultural. Temas psicol., Ribeirão Preto, v. 17, n. 2, p. 511-525, 2009.

15. SILVA NN. A diversidade cultural como princípio educativo. Paidéia: r. do cur. De peg. Da Fac. de Ci. Hum., Soc. E da Saú., Univ. Fumec, n.11, p. 13-29, jul/dez 2011.

16. VYGOSTKY LS. Obras Escogidas III: problemas del desarrollo de la psique. $2^{\underline{a}}$ ed. Madrid: Visor Dis, 2000.

17. ZABALZA M. Como educar em valores na escola. Revista Pátio Pedagógica. Ano 4, no 13, mai/jul. 2000. 